ORIGINAL ARTICLE

\title{
Assessment of Cartilage Strip and Bone Cement in Ossiculoplasty
}

\section{Magdy Ibrahem Gouda, Mohammad Abdel Azeem Mohammad, Hazem Saeed Mohammad, Ahmad Mohammad Abdel Hameed Abdel Ghany}

\begin{abstract}
Professor of Otorhinolaryngology, Faculty of Medicine - Zagazig University Professor of Otorhinolaryngology, Faculty of Medicine - Zagazig University, Professor of Otorhinolaryngology, Faculty of Medicine - Zagazig University, M.Sc. Otorhinolaryngology, Faculty of medicine zagazig university
\end{abstract}

Corresponding Author:

Ahmad Mohammad Abdel Hameed Abdel Ghany

AhmadAbdelHameed96@gmail.com M.Sc. Otorhinolaryngology, Faculty of medicine zagazig university

\section{ABSTRACT}

Background and aim: Complete disruption of the ossicular chain can result in up to $60 \mathrm{~dB}$ hearing loss. Hearing restoration surgery comprises ear drum repair and ossicular chain reconstruction in ears housing defective ossicles. The aim of this study was to assess cartilage strip and bone cement in ossiculoplasty.

Patients and methods: This is a prospective, cross sectional study and was carried out on 36 patients ( 27 females and 9 males) with chronic suppurative otitis media, their age ranged from 12 to 38 years. Patient were subjected to complete history taking, complete ENT examination, preoperative audiological evaluation, high resolution computed tomography "HRCT" and complete laboratory investigations. All patients were operated by tympanomastoidectomy for eradication of middle ear pathology ( 21 cases underwent canal wall up technique while 15 cases underwent canal wall down technique), Then reconstruction of the ossicular chain was done by cartilage strip and bone cement (30cases between malleus to stapes while 6 cases between incus to stapes). Postoperative assessment done by pure tone audiometry \& tympanometry $3 \& 6$ months postoperatively.

Results: Regarding improvement in hearing $83.3 \%$ of our patient were improved while the remaining $16.7 \%$ were not. The result of pure tone audiometry \& typanometry were significantly improved $(\mathrm{p}=0.0008)$. Graft taken occur in $83.3 \%$ of cases.

Conclusions: The usage of bone cement with a cartilage strip is a simple and effective method for ossicular reconstruction and associated with significant improvement in conductive hearing loss.

Keys word: Ossiculoplasty, Bone cement, Cholesteatoma, Cartilage strip, Reconstruction.

\section{INTRODUCTION}

Q ver recent years, continuous reconstruction to restore hearing as much as normal hearing. This is the results of a better understanding of biomechanics of the ossicular chain, leading to an effective columellar effect, in addition to the appearance of new types and new materials of prosthesis. ${ }^{(1)}$
Currently, many materials are utilized in ossiculoplasty. The advantages of use of autologous material (cartilage, ossicles or bone cortex) are easy and cheap to be harvested from the patient. In a condition with absence of autologous material or in functional failure, ossicular prosthesis were subsequently developed. The role of these prosthesis is to transmit the sound wave from the tympanic membrane to the stapedial head, either directly, or indirectly. Inspite of the 
presence of various types of materials (titanium, gold, hydroxyapatite, steel, ceramics, teflon etc.), titanium and hydroxyapatite (HAP) prosthesis are the most commonly used materials in ossiculoplasty. ${ }^{(2)}$

Bone cement was developed in the 1970s and started to use in dental practice. It has good biocompatibility and present new bone formation on applied ossicles. In addition to having well tissue biocompatibility, the usage of bone cement is very easy and much more economical than the prostheses. Bone cement is prepared and shaped easily and after getting hard it doesn't get affected by any fluids like blood. ${ }^{(3)}$

Bone cements are substances produced by an acid-base reaction. This means that formulated powder is mixed with a liquid to generate a mixture that hardens through a reaction. Classification of cements can be performed according to their chemical contents as the following: phosphate cement (Zinc Oxide "ZnO" powder and phosphoric acid liquid), carboxylate cement ( $\mathrm{ZnO}$ powder and polyacrylic acid liquid), silicate cement (glass powder and phosphoric acid liquid), and glass ionomer cement (glass powder and polyacrylic liquid). ${ }^{(4)}$

\section{PATIENTS AND METHODS}

This is a prospective, cross sectional study and was carried out on 36 patients (27 females and 9 males), their age ranged from 12 to 38 years. Patients were selected from outpatient clinic of ENT department, Zagazig university hospitals in the period from December 2015 to December 2017. Table (1)

They all were complaining of chronic suppurative otitis media "CSOM" (bilateral 9 cases, left 15 cases \& right 12 cases) with ossicular discontinuity diagnosed by ABG more than $40 \mathrm{db}$ (preoperatively), ossicular discontinuity seen or absent round window reflex (intraoperatively), with or without history of previous ear surgery and presented by hearing loss, discharge, vertigo, tinnitus and/or headache. The patients with poor general condition, active infection in the affected ear were excluded. Table (2), Table (3)

Written informed consent was obtained from all participants and the study was approved by the research ethical committee of Faculty of
Medicine, Zagazig University. The work has been carried out in accordance with The Code of Ethics of the World Medical Association (Declaration of Helsinki) for studies involving human.

All selected patients were subjected to good preoperative evaluation in the form of complete history taking, complete ENT examination, preoperative audiological evaluation (pure tone audiometry \& tympanometry), high resolution computed tomography ( axial \& coronal cuts) and complete laboratory investigations.

Surgical technique : Post auricular incision, Elevation of tympanomeatal flap, exploration of middle ear and mastoid cavity (21 cases underwent CWU and 15 cases underwent CWD), removal of granulation tissue (GT) and cholesteatoma if present, examination of ossicular continuity, evaluation of Eustachian tube orifice patency, Reconstruction of ossicular continuity using a thin cartilage strip from conchal cartilage tailored according to the gap between ossicles supported with bone cement prepared just before application by mixing minimal amount of bone cement powder with one drop of saline until become gelatinous in consistency between lateral process (manubrium) of malleus and head of stapes (30 cases) or between the remaining part of long process of incus and head of stapes (6 cases), we protect middle ear during application of bone cement using gel foam around footplate of stapes \& over the promontory, bone cement applied over ossicles needed to be connected then we put cartilage strip over bone cement mixture then we cover cartilage strip with bone cement and wait for 10 minutes. Figure (1),Figure (2) Grafting of tympanic membrane was done using chondroperichondial graft from conchal cartilage about $1 \mathrm{~cm} \times 1.5 \mathrm{~cm}$ (cartilage strip separated from it using scalp 15 , about $1 \mathrm{~mm}$ width, $1 \mathrm{~mm}$ height $\&$ its length according to gap between ossicles needed to be reconstructed and the remaining part thinned to be used for grafting of tympanic membrane). Gel foam settled in middle ear cavity and in external canal then 2 packs inserted in external canal to be removed "outer one after one week and inner one after 
Gouda MI, et al..

two weeks", then closure of the post auricular incision. Table (4)

Postoperative management $\&$ follow up : Antibiotic (systemic), analgesia, antiinflammatory \& nasal decongestant if not cardiac or hypertensive. Postoperative otoscopic examination was conducted at $2 \mathrm{nd}$, $3 \mathrm{rd}$, 4th and 5th weeks postoperatively then done at 2nd, 3rd, 4th, 5th and 6th months after removal of aural packs. Post-Operative pure tone audiometry \& tympanometry examination were held at 3rd and 6th months postoperatively. Table (5)

\section{STATISTICAL ANALYSIS}

Data collected throughout history, basic clinical examination, laboratory investigations and outcome measures coded, entered and analyzed using Microsoft Excel software. Data were then imported into Statistical Package for the Social Sciences (SPSS version 20.0) software for analysis. According to the type of data qualitative represent as number and percentage, quantitative continues group represent by mean $\pm \mathrm{SD}$, the following tests were used to test differences for significance Difference and association of qualitative variable by Chi square test $\left(X^{2}\right)$. Differences between quantitative independent groups by $t$ test paired by paired $t$ or Sign. $P$ value was set at $<0.05$ for significant results $\&<0.001$ for high significant result.

\section{RESULTS}

This study included 36 patients. 27 (75\%) females and 9 (25\%) males. Their age ranged from 12 to 38 years; mean age $=21.41$ and the standard deviation is 8.21 (Mean \pm $\mathrm{SD}=21.41 \pm 8.21)$. Table (1)

$41.7 \%$ of patients were having past history of ear operations, while the other $58.3 \%$ were not. Table (1)

Regarding presented symptoms and signs:

- Regarding ear discharge, $25 \%$ of patients were complaining of bilateral ear discharge, $41.7 \%$ of them were complaining of left ear

\section{Zagazig University Medical Journals}

dishcarge while the last $33.3 \%$ were complaining of right ear discharge. Table (2)

- Regarding hearing loss, 25\% of patients were presented by bilateral hearing loss, $41.7 \%$ of them were presented by left ear hearing loss and the other $33.3 \%$ right ear hearing loss. Table (2)

- Regarding Tinnitus, $83.3 \%$ were presented by tinnitus while the others were not. Table (2)

- Regarding Vertigo, $16.7 \%$ were presented by vertigo while the other were not. Table (2)

- Headache were presented in only $25 \%$ of cases. Table (2)

- Ear pain and Facial nerve problems were not presented in any of our patients. Table (2) Cholesteatoma were found in $75.0 \%$ of cases. Table (3)

Perforation were found in $100.0 \%$ of cases, in $75.0 \%$ of them the perforation were marginal, while it was central in $25.0 \%$ of cases. Table (3)

In $58.3 \%$ of patients, the middle ear and mastoid process were explored by using the canal wall up "CWU" technique, while in the other $41.7 \%$ of patients the canal wall down "CWD" technique were used. Table (4)

Ossicular reconstruction were done $16.7 \%$ of patients by reconnecting Incus to stapes, while in the majority of cases $(83.3 \%)$ reconstruction were done by reconnecting handle of malleus to stapes due to complete absence of the incus. Table (4)

Graft were taken (success) in only $83.3 \%$ of cases. Table (4)

Regarding pre- and post-operative audiological assessment, our results showed that the PTA and tympanometry were significantly improved along our study and best results were obtained at the 6 months evaluation. Table (5)

Regarding improvement in hearing of our patients, $83.3 \%$ were improved while the other $16.7 \%$ were not improved. Table (5) 
Table 1. Demographic and clinical characters distribution among studied group:

\begin{tabular}{|c|c|}
\hline 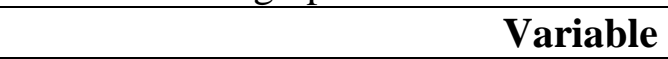 & \\
\hline $\begin{array}{l}\text { Age: } \\
\text { - Mean } \pm \text { SD } \\
\text { - Median } \\
\text { - range }\end{array}$ & $\begin{array}{c}21.41 \pm 8.21 \\
20.0 \\
12-38 \\
\end{array}$ \\
\hline Variable & No $(\%)$ \\
\hline $\begin{array}{l}\text { Sex: } \\
\text { - Female } \\
\text { - Male }\end{array}$ & $\begin{array}{c}27(75.0 \%) \\
9(25.0 \%)\end{array}$ \\
\hline $\begin{array}{l}\text { Past History of ear surgery: } \\
-\quad-\mathrm{VE} \\
-\quad+\mathrm{VE}\end{array}$ & $\begin{array}{l}21(58.3 \%) \\
15(41.7 \%)\end{array}$ \\
\hline $\begin{array}{l}\text { CSOM: } \\
\text { - Bilateral } \\
\text { - Left } \\
\text { - Right }\end{array}$ & $\begin{array}{c}9(25.0 \%) \\
15(41.7 \%) \\
12(33.3 \%)\end{array}$ \\
\hline Total & $36(100.0 \%)$ \\
\hline
\end{tabular}

Table 2. Sign and symptoms distribution among studied group

\begin{tabular}{|c|c|}
\hline Variable & No (\%) \\
\hline $\begin{array}{l}\text { Hearing Loss: } \\
\text { - Bilateral } \\
\text { - Left } \\
\text { - Right }\end{array}$ & $\begin{array}{c}9(25.0 \%) \\
15(41.7 \%) \\
12(33.3 \%)\end{array}$ \\
\hline $\begin{array}{l}\text { Ear discharge } \\
\text { - Bilateral } \\
\text { - Left } \\
\text { - Right }\end{array}$ & $\begin{array}{c}9(25.0 \%) \\
15(41.7 \%) \\
12(33.3 \%)\end{array}$ \\
\hline $\begin{array}{l}\text { Tinnitus: } \\
- \text {-VE } \\
-+ \text {-VE }\end{array}$ & $\begin{array}{c}6(16.7 \%) \\
30(83.3 \%)\end{array}$ \\
\hline $\begin{array}{l}\text { Vertigo: } \\
- \text {-VE } \\
-+V E\end{array}$ & $\begin{array}{c}30(83.3 \%) \\
6(16.7 \%)\end{array}$ \\
\hline $\begin{array}{l}\text { Facial nerve: } \\
- \text {-VE } \\
-+ \text { VE }\end{array}$ & $\begin{array}{c}36(100.0 \%) \\
0(00.0 \%)\end{array}$ \\
\hline $\begin{array}{l}\text { Headache: } \\
-- \text { VE } \\
-+\mathrm{VE}\end{array}$ & $\begin{array}{c}27(75.0 \%) \\
9(25.0 \%)\end{array}$ \\
\hline $\begin{array}{l}\text { Pain: } \\
--V E \\
-+V E \\
\end{array}$ & $\begin{array}{c}36(100.0 \%) \\
0(00.0 \%)\end{array}$ \\
\hline Total & $36(100.0 \%)$ \\
\hline
\end{tabular}


Table 3. Perforation and Cholesteatoma distribution among studied group:

\begin{tabular}{|l|c|}
\hline Variable & No (\%) \\
\hline Cholesteatoma: & $\mathbf{9 ( 2 5 . 0 \% )}$ \\
- No & $\mathbf{2 7}(\mathbf{7 5 . 0 \% )}$ \\
\hline - Yes & \\
\hline Perforation: & $\mathbf{2 7}(\mathbf{7 5 . 0 \%})$ \\
- Marginal or Attic & $\mathbf{9 ( 2 5 . 0 \% )}$ \\
\hline - Central & $\mathbf{3 6}(\mathbf{1 0 0 . 0 \%})$ \\
\hline Total & \\
\hline
\end{tabular}

Table 4. Intra-operative details and characters:

\begin{tabular}{|l|c|}
\hline Variable & No $(\%)$ \\
\hline Operation Technique: & \\
- CWU & $\mathbf{2 1}(58.3 \%)$ \\
- CWD & $\mathbf{1 5}(\mathbf{4 1 . 7 \% )}$ \\
\hline Technique of connection: & $\mathbf{6 ( 1 6 . 7 \% )}$ \\
- Incus to Stapes. & $\mathbf{3 0}(\mathbf{8 3 . 3 \%})$ \\
\hline - Malleus to Stapes. & \\
\hline Taken Graft: & $\mathbf{6}(16.7 \%)$ \\
- No & $\mathbf{3 0}(\mathbf{8 3 . 3 \%})$ \\
- Yes & $\mathbf{3 6}(\mathbf{1 0 0 . 0 \%})$ \\
\hline Total & \\
\hline
\end{tabular}

Table 5 Pure tone audiometry and Tympanometry pre and post operative among studied group:

\begin{tabular}{|lc|c|c|c|}
\hline \multicolumn{1}{|c|}{ PTA Tympanometry } & Pre-operative & $\begin{array}{c}3 \text { months } \\
\text { Post-operative }\end{array}$ & $\begin{array}{c}6 \text { months } \\
\text { Post-operative }\end{array}$ \\
\hline - Mean + SD & & $30.41 \pm 7.3$ & $22.08 \pm 17.3$ & $16.25 \pm 12.2$ \\
- Median & & 30.0 & 17.5 & 10.0 \\
- range & $20-38$ & $5-60$ & $5-45$ \\
\hline \multicolumn{4}{r}{ Base \& 3 month $P=0.0001 * *$} \\
Base and 6 month $p=0.00 * *$ \\
3 month and 6 month $p=0.0008 * *$ \\
\hline
\end{tabular}
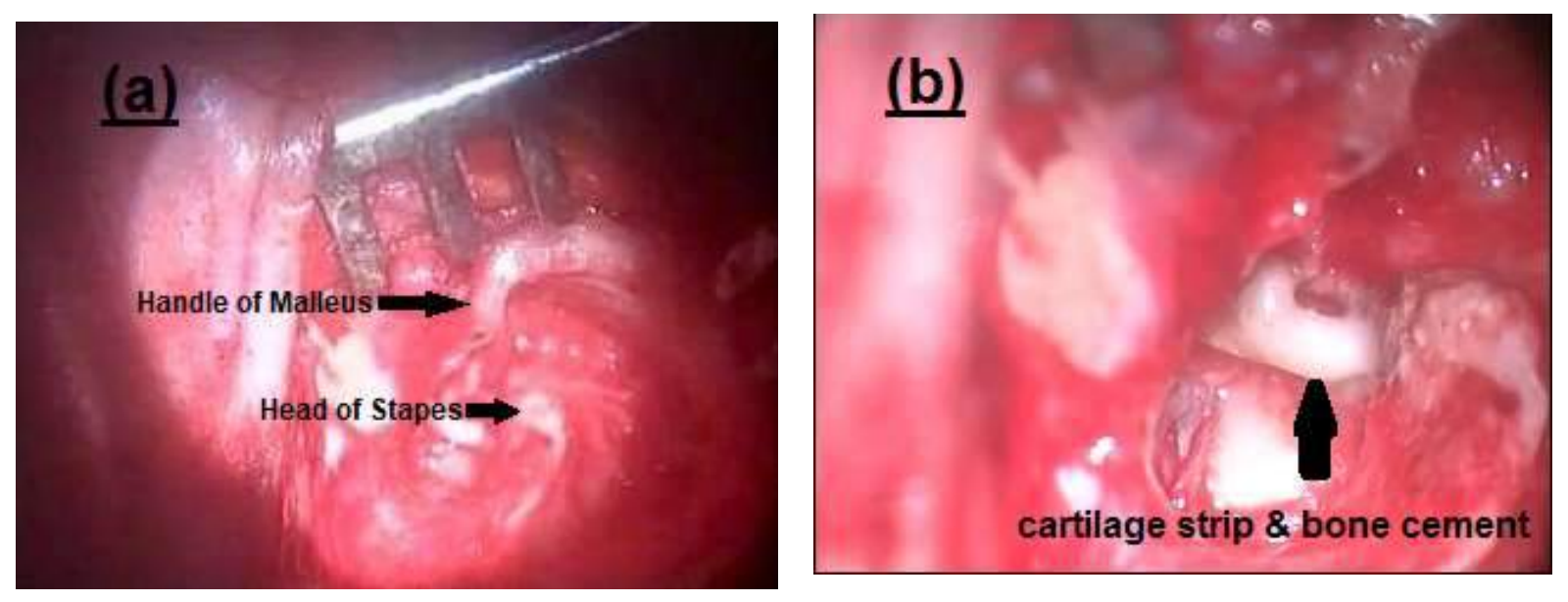

Figure 1: a) Showing gap between handle of malleus \& head of stapes.

b) Showing reconstruction of ossicular chain using cartilage strip \& bone cement between handle of malleus \& head of stapes. 

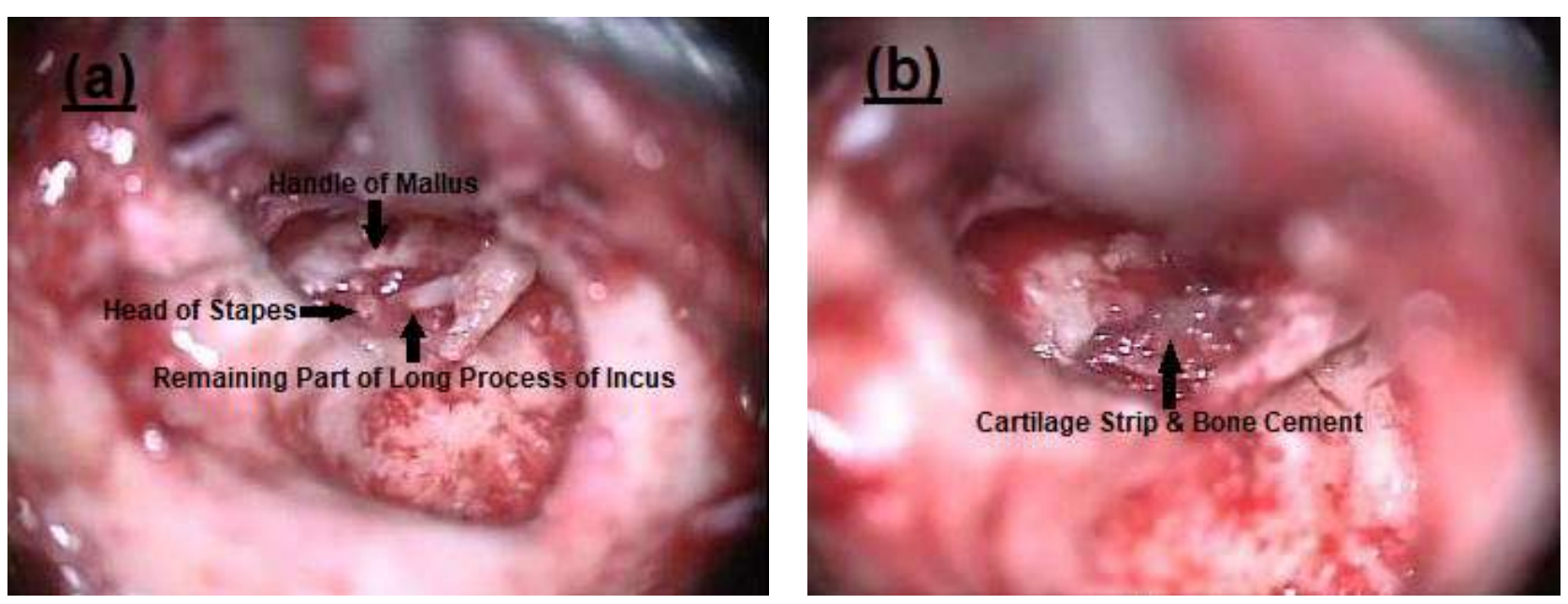

Figure 2: a) Showing gap between remaining part of long process of incus and head of stapes

b) Showing reconstruction of ossicular chain using cartilage strip and bone cement between remaining part of long process of incus and head of stapes.

\section{DISCUSSION}

Hearing loss from ossicular chain dysfunction may be secondary to developmental abnormalities, cholesteatoma, trauma, tympanosclerosis , otosclerosis, and inflammation $^{(5)}$.

Ossicular reconstruction procedures have been continuously improved over recent decades in order to restore hearing as close as possible to physiological hearing in patients with an interrupted ossicular chain. This continuing progress is the results of a better knowledge of ossicular biomechanics, resulting in an effective columellar effect, as well as the development of new materials and new types of prostheses ${ }^{(\mathbf{1})}$.

The objectives of these developments were to provide a substitute combining stability, acoustic impedance and biocompatibility, while ensuring stability of these properties over time ${ }^{(6)}$.

Different types of materials are used in ossiculoplasty procedures including autologous material, such as cartilage, ossicles or bone cortex that can be easily and inexpensively harvested from the patient are used $^{(7)}$.

Ionomeric bone cement has become available for otological surgery, where it has been effectively used to stabilize prostheses in the presence of active otosclerosis, to fill mastoidectomy cavities and to anchor certain types of active middle ear implants. It has also been shown to be useful in reconstruction of the ossicular chain in the context of isolated destruction of the long process of the incus.Despite its obvious advantages, use of this material has been associated with several serious complications (encephalopathy) related to the presence of aluminium in its composition, which is why hydroxyapatite (HAP) bone cement has been developed as an alternative to ionomeric cement, as the safety of HAP in middle ear surgery has been demonstrated for a long time ${ }^{(\mathbf{1})}$.

The aim of this study was to assess cartilage strip and bone cement in ossiculoplasty as a new technique.

Regarding demographic distribution, our result showed that female patients were more than male patients with age ranging between 12 to 38 years, while in the study done by Kumar et al., (6) male patients were more than female patients \& their age ranging between 12 to 56 years.

Regarding cholesteatoma, ossicular discontinuity more common with Cholesteatoma in $75 \%$ of cases, similar to us Haidar et al. ${ }^{(8)}$ \& Varshney et al. ${ }^{(9)}$

Regarding technique used in exploration of middle ear cavity, the CWU technique used more than CWD technique, similar to us Kotzias et al. ${ }^{(10)}$

Regarding hearing assessment, significant difference between pre \& post hearing with best results were obtained at the 6 month evaluation indicating success of our 
procedure, similar to us Kumar et al. ${ }^{(6)} \&$ Lahlou et al. ${ }^{(11)}$

The significant association between final outcomes and graft taken was supported by Kumar et al. ${ }^{(6)}$

Regarding the usage of bone cement in our procedure, many studies had supported this usage as cementoplasty allows preservation of the incus-malleus joint, resulting in improved stability of the reconstruction with virtually no risk of secondary displacement ${ }^{(1)}$.

Edizer et al., ${ }^{(12)}$ reported in their study that Bone cements have ideal osseointegrative and adhesive properties and malleus to stapes bone cement rebridging may provide hearing results comparable with stapes bone cement rebridging and incus interposition.

To the best of our knowledge, we are the first study to use cartilage strip and bone cement as a single technique for ossicular reconstruction.

\section{CONCLUSION}

The usage of bone cement with a cartilage strip is a simple and effective method for ossicular reconstruction and associated with significant improvement in conductive hearing loss.

\section{Declaration of interest}

The authors report no conflicts of interest. The authors alone are responsible for the content and writing of the paper.

Funding information

None declared

\section{REFERENCES}

1. Galy-Bernadoy C, Akkari M, Mathiolon C, Mondain M, Uziel $A$ and Venail $F$ (2014): Comparison of early hearing outcomes of type 2 ossiculoplasty using hydroxyapatite bone cement versus other materials. European Annals of Otorhinolaryngology, Head and Neck diseases, 131; 289-292.

2. Kong JS, Jeong CY, Shim MJ, Kim WJ, Yeo SW and Park SN (2018): Comparative study of new autologous material, bone-cartilage composite graft, for ossiculoplasty with Polycel and Titanium. Clin Otolaryngol. 2018 April: 43(2):434-439.

3. Kalcioglu MT, Tan M and Fleerakkers J (2013): The use of Bone-cement for ossicular chain defects. Eur Arch Otorhinolaryngol, 270: 2849-2855.

4. Bayazit YA, Ozer E, Kanlikama M, Durmaz $T$ and Yilmaz $M$ (2005): Bone Cement Ossiculoplasty: Incus to Stapes Versus Malleus to Stapes Cement Bridge. Otol Neurotol. 2005 May;26(3):364-7.

5. Isaacson B, Wick $C$ and Hunter $J$ (2017): Endoscopic ossiculoplasty. Operative Techniques in Otolaryngology -Head and Neck Surgery, 28 (1): 39-43.

6. Kumar S, Yadav K, Ojha T, Sharma A, Singhal $A$ and Gakhar $S$ (2017): To Evaluate and Compare the Result of Ossiculoplasty Using Different Types of Graft Materials and Prosthesis in Cases of Ossicular Discontinuity in Chronic Suppurative Otitis Media Cases. Indian J Otolaryngol Head Neck Surg, 70; 1:15-21.

7. Wegner I, van den Berg JW, Smit AL, Grolman W (2015): Systematic Review of the Use of Bone Cement in Ossicular Chain Reconstruction and Revision Stapes Surgery. Laryngoscope. 125(1):227-33.

8. Haidar H, Sheikh R, Larem A, Elsaadi A, Abdulkarim H, Ashkanani $\mathrm{S}$ and Alqahtani A (2015): Ossicular Chain Erosion in Chronic Suppurative Otitis Media. Otolaryngol (Sunnyvale) 5:203-2.

9. Varshney S, Nangia A, Bist SS, Singh RK, Gupta N and Bhagat $S$ (2010): Ossicular chain status in chronic suppurative otitis media in adults. Indian J Otolaryngol Head Neck Surg, 62; 4:421-6.

10. Kotzias SA, Seerig MM, Mello MFPC, Chueiri L, Jacques J, Silva MBCD and Zatt DB (2018): Ossicular chain reconstruction in chronic otitis media: hearing results and analysis of prognostic factors. Braz J Otorhinolaryngol, pii: S18088694; 18:30741-9.

11. Lahlou G, Sonji G, De Seta D, Mosnier I, Russo FY, Sterkers $O$ and Bernardeschi D (2018): Anatomical and functional results of ossiculoplasty using titanium prosthesis. Acta Otorhinolaryngol Ital, 38; 4: 377-383.

12. Edizer DT, Durna YM, Hamit B, Demirhan $H$ and Yigit $O$ (2016): Malleus to Stapes Bone Cement Rebridging Ossiculoplasty: Why Don't We Perform Frequently? Ann Otol Rhinol Laryngol, 125; 6:445-51.

To Cite This Article: Gouda MI, Mohammad MA, Mohammad HS .Assessment of Cartilage Strip and Bone Cement in Ossiculoplasty. ZUMJ 2019;25(5);595-600,DOI: 10.21608/zumj.2019.10415.11000 